\title{
A Theoretical Investigation of Gas Phase OH-Initiated Acenaphthylene Degradation Reaction
}

\author{
Xin Mao, Sufan Wang*, Yucheng Huang, Tao Zhou \\ College of Chemistry and Materials Science, Anhui Normal University, Wuhu, China \\ Email: *sfwang@mail.ahnu.edu.cn
}

How to cite this paper: Mao, X., Wang, S.F., Huang, Y.C. and Zhou, T. (2017) A Theoretical Investigation of Gas Phase $\mathrm{OH}$ Initiated Acenaphthylene Degradation Reaction. Computational Chemistry, 5, 22-37. http://dx.doi.org/10.4236/cc.2017.51003

Received: September 7, 2016

Accepted: January 3, 2017

Published: January 6, 2017

Copyright $\odot 2017$ by authors and Scientific Research Publishing Inc. This work is licensed under the Creative Commons Attribution International License (CC BY 4.0).

http://creativecommons.org/licenses/by/4.0/

\begin{abstract}
The mechanisms for $\mathrm{OH}$-initiated acenaphthylene degradation reactions are investigated theoretically by using the density function theory method at M06-2X/aug-ccpVTZ level in the present paper. There are two possible reaction pathways for the degradation processes have been predicted: the hydrogen abstraction pathway and the hydroxyl addition elimination pathway. Additionally, the formation mechanism for a series of the products such as epoxide, naphthalene-1,8-dicarbaldehyde, dialdehydes, 1-acenaphthenone and nitroacenaphthylene are discussed in detail as well. From the analyses of the decomposition of $\mathrm{OH}$-acenaphthylene adducts, it is found that the favorable reaction with $\mathrm{O}_{2} / \mathrm{NO}$ is to form the acenaphthenone rather than epoxide, and the most stable isomer is acenaphthenone react from the $\mathrm{C} 1$-site reaction. The advantage reaction pathway with $\mathrm{NO}_{2}$ is to form nitroacenaphthylene and nitroacenaphthylenol from C1-site, too.
\end{abstract}

\section{Keywords}

Polycyclic Aromatic Hydrocarbons, Acenaphthylene, Gas Phase,

Nitroacenaphthylene, Degradation

\section{Introduction}

It is confirmed that the emission of the organic compounds especially polycyclic aromatic hydrocarbons (PAHs) can lead to photochemical air pollution, acid deposition and ozone depletion after a series of complex chemical and physical transformation [1]. These toxic air pollutants can also exert some diverse influence on human-beings, such as lung cancer [2]. The researches show that with the increase of the number of aromatic ring, the carcinogenic will increase too [3]. The aromatic compounds in polluted atmospheres are aromatic hydrocarbons and their derivatives, such as aromatic alde- 
hydes, phenolic compounds and nitro-polycyclic aromatic hydrocarbons [4] [5] [6] [7] [8]. Since the last century, there are many parallel experimental studies in laboratory and ambient atmospheric about PAHs and its derivatives [9] [10] [11]. Recently, there is an increasing interest in the mechanism studies of the gas-phase tropospheric chemistry of PAHs, such as naphthalene [9], anthracene [12], phenanthrene [13] [14], triphenylene [15], 9,10-dichlorophenanthrene [16], DDT [17] and benzo[a]pyrene [3].

The PAHs in air can undergo the gas-phase chemically transformation by hydroxyl $(\mathrm{OH})$ radical, ozone [18], nitrate $\left(\mathrm{NO}_{3}\right)$ radical [16], $\mathrm{N}_{2} \mathrm{O}_{5}$, and photolysis reaction [17]. To date, the PAHs degradation by radical especially $\mathrm{OH}$ radical is a promising approach to eliminate the PAHs from environment. Acenaphthylene, as the most abundant PAH in polluted urban areas, now has been drawn considerable attention because the reactions of acenaphthylene degradation process often yield secondary species which may be more carcinogenic and more mutagenic than acenaphthylene itself [9]. Acenaphthylene is mainly derived from the off-gas of gasoline automobile, cooking fumes [19] [20] and diesel exhaust [21]. The kinetic studies and the possible products about the degradation of acenaphthylene have been reported recently [19] [22]. In their reports, it is supposed that the intermediates of the $\mathrm{OH}$ radical degradation process can also undergo the secondary reaction with $\mathrm{O}_{2}$ and $\mathrm{NO}_{\mathrm{x}}$ gas phase chemical reactions. And the products may be epoxide, naphthalene-1,8-dicarbaldehyde, dialdehydes, 1acenaphthenone and some nitroacenaphthylene. Due to the lack of the detailed mechanism in their work, it is not sufficient for one to understand the reactions and the mechanisms comprehensively. Herein this work, we predicted the possible reaction channels by specifying the reaction sites of acenaphthylene and discussed the processes of $\mathrm{OH}$-initiated acenaphthylene with the hydrogen abstraction and the hydroxyl addition-elimination pathways theoretically. Furthermore, the possible secondary reactions based on the stable intermediates have been proposed, and a reasonable explain on how these secondary products come into being was highlighted, which may give a supporting for the relevant experimental research.

\section{Computational Methods}

All of the calculations involved in this work were performed by using Gaussin09 package of programs [23]. M06-2X/aug-cc-pVTZ level of theory was chosen for the stationary point geometry optimization and frequency calculations, which is believed that the extra exchange-correlation functional included for accurate thermochemical and kinetical calculations especially [24]. This method has been identified by a couple of relevant gas phase radical oxidation reactions [25] [26]. Furthermore, the intrinsic reaction coordinates (IRC) approach calculations were carried out at the same level in order to verify the designed transition structures connecting to the expected energy minima. The corresponding energy embedded with the reaction scheme were all corrected, where the energy barriers $\Delta E$ is corrected by the Zero-Point Energy and reaction enthalpies $\Delta H$ is corrected with thermodynamic correction respectively. The z-matrix of optimized geometries for the reactants, intermediates and transition states calculated with M06-2X/aug-cc-pVTZ method are provided in Supplemental Information. 


\section{Results and Discussion}

\subsection{OH-Initiated Acenaphthylene Reaction}

Due to acenaphthylene is a $\mathrm{C}_{2 \mathrm{v}}$ axial symmetrical molecule, there are totally 6 alternative potential reaction sites. For convenience to discuss the following contents, the $\mathrm{C}$ atoms of acenaphthylene are numbered as presented in Figure 1.

\subsubsection{Hydrogen Abstraction Pathway}

The $\mathrm{OH}$-initiated acenaphthylene degradation reaction can result in $\mathrm{H}$-atom abstraction from the conjugated ring by the stronger $\mathrm{H}$-bonding interaction between the $\mathrm{H}$ atoms and the $\mathrm{O}$ atom of $\mathrm{OH}$ radical. The reaction can take place at $\mathrm{C} 1, \mathrm{C} 3, \mathrm{C} 4$ and $\mathrm{C} 5$ sites through four alternative transition states to form the corresponding ring radical and a water molecule as the reaction scheme depicted in Figure 2. All these transition state structural characters are similar, the $\mathrm{OH}$ radical approaches to acenaphthylene by $\mathrm{H}$-bonding interaction with a classical linear linkage to the $\mathrm{H}$ atom in the conjugated ring. Compared the corresponded $\mathrm{C}-\mathrm{H}$ and $\mathrm{O}-\mathrm{H}$ single bond in transition states, it is clear to find that the $\mathrm{C}-\mathrm{H}$ single bond in TS1 is longer than others, and meanwhile $\mathrm{O}-\mathrm{H}$ bond is shorter than other transition states.

The calculated results show that the $\mathrm{OH}$ radical abstraction reaction from $\mathrm{C} 3, \mathrm{C} 4$ and $\mathrm{C} 5$-site are energetically the more favorable ones compared with the $\mathrm{C} 1$ reaction site due to the lower potential barriers. Comparing the energy of products $\mathrm{P} 1$ to $\mathrm{P} 4$, the product $\mathrm{P} 1$ is the most unstable isomer with about $2.0 \mathrm{kcal} / \mathrm{mol}$ higher energy than the others. Overall, at the M06-2X/aug-cc-pVTZ theoretical level, from the reaction probability and the isomer stability, we can draw the primary conclusion that the hydrogen abstraction reaction can result in the acenaphthylene radical isomers with comparable stability.

\subsubsection{Hydroxyl Addition Pathways}

Because of the resourceful negative charge on the $\mathrm{O}$ atom of $\mathrm{OH}$ radical, the $\mathrm{OH}$ radical can append to the $\mathrm{C} 1$ to $\mathrm{C} 6$ reaction sites of acenaphthylene molecule leading to six primary processes to form corresponding $\mathrm{OH}$-initiated acenaphthylene radicals (as shown in Figure 3). Herein, there are six transition state structures identified with the $\mathrm{O}$ atom of the $\mathrm{OH}$ radical linking to the individual carbon atoms from one side of the aromatic molecular ring plane. The structures of these transition states are similar, the new formed $\mathrm{C}-\mathrm{O}$ bonds are all perpendicular to the corresponding conjugated ring, respectively.

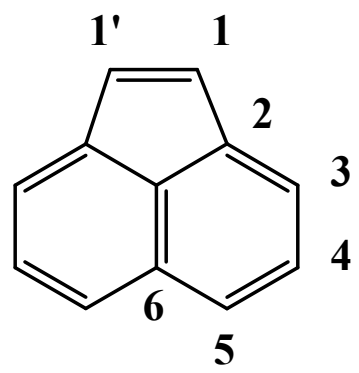

Figure 1. The structure of acenaphthylene with C-atom labeling. 


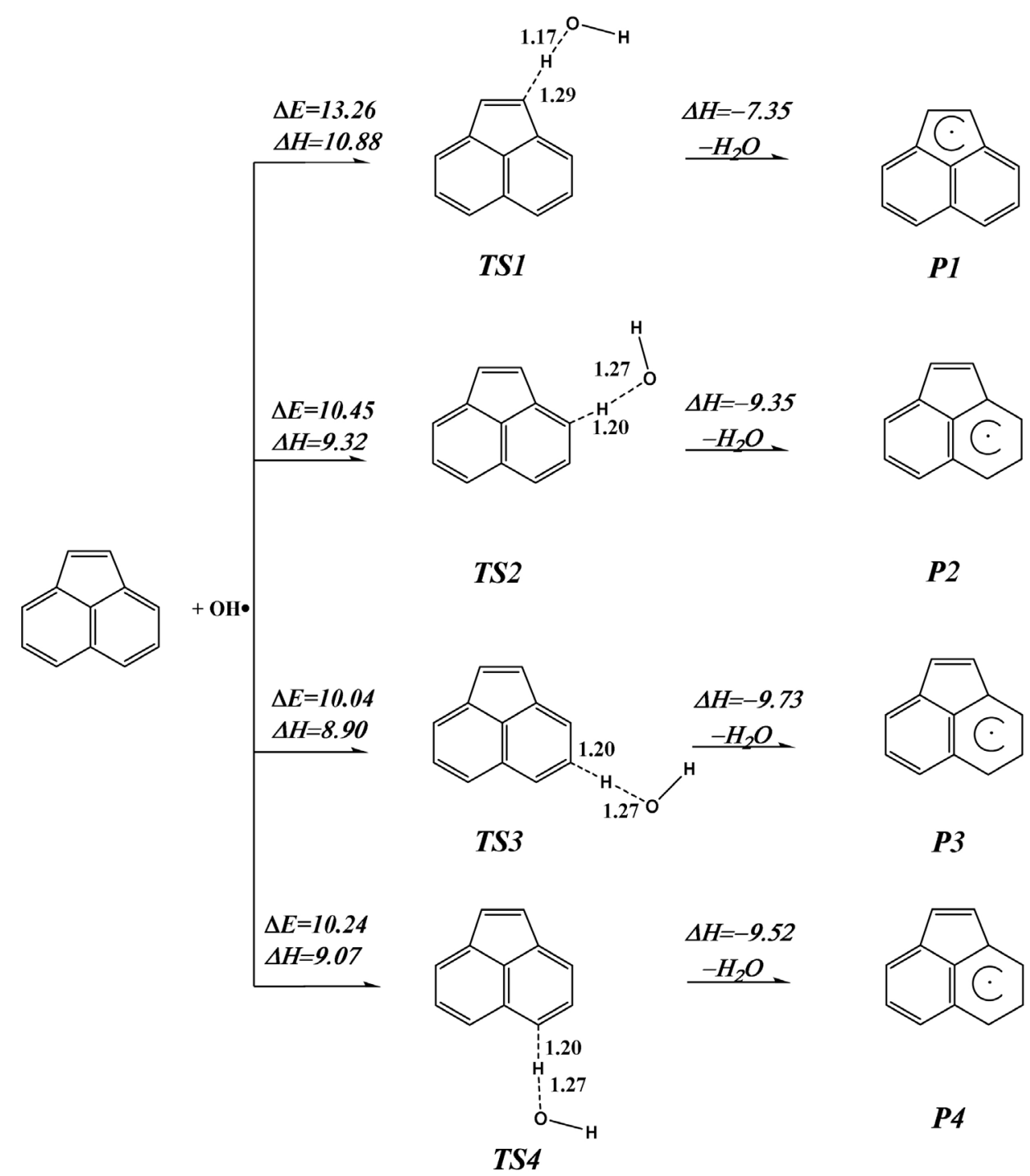

Figure 2. Proposed reaction pathways of $\mathrm{H}$ abstraction to acenaphthylene at the M06-2X/ aug-cc-pVTZ level of theory.

The reaction scheme embedded with the energy barriers $\Delta E(\mathrm{kcal} / \mathrm{mol})$ and reaction enthalpies $\Delta H(\mathrm{kcal} / \mathrm{mol})$ is presented in Figure 3 as well. The calculated results show that $\mathrm{C} 1$-site $\mathrm{OH}$ radical addition is energetically the most favorable reaction pathway because of the lowest barrier and the strongest exothermicity, which indicates that the dominant reaction site for the $\mathrm{OH}$ addition to acenaphthylene is the unsaturated bond in the cyclopenta-fused ring. The potential barrier for P5 formation at the M06$2 \mathrm{X} /$ aug-cc-pVTZ level is $0.25 \mathrm{kcal} / \mathrm{mol}$ and the reaction enthalpies is $-33.33 \mathrm{kcal} / \mathrm{mol}$. The C6 site reaction is the most impossible way to occur because of the highest reaction barrier $(17.35 \mathrm{kcal} / \mathrm{mol})$.

As these two reaction channels show that the reaction activity of the different $\mathrm{C}$ sites is anisotropic. Generally, acenaphthylene tends to the hydroxyl addition reaction to form much more stable $\mathrm{OH}$-initiated acenaphthylene radical. Well $\mathrm{C} 1$ is the best reaction site for the hydroxyl addition reaction to form the most stable radical isomer P5. C3, C4 and C5 are having the similarity reaction activity in both reaction channels. The 


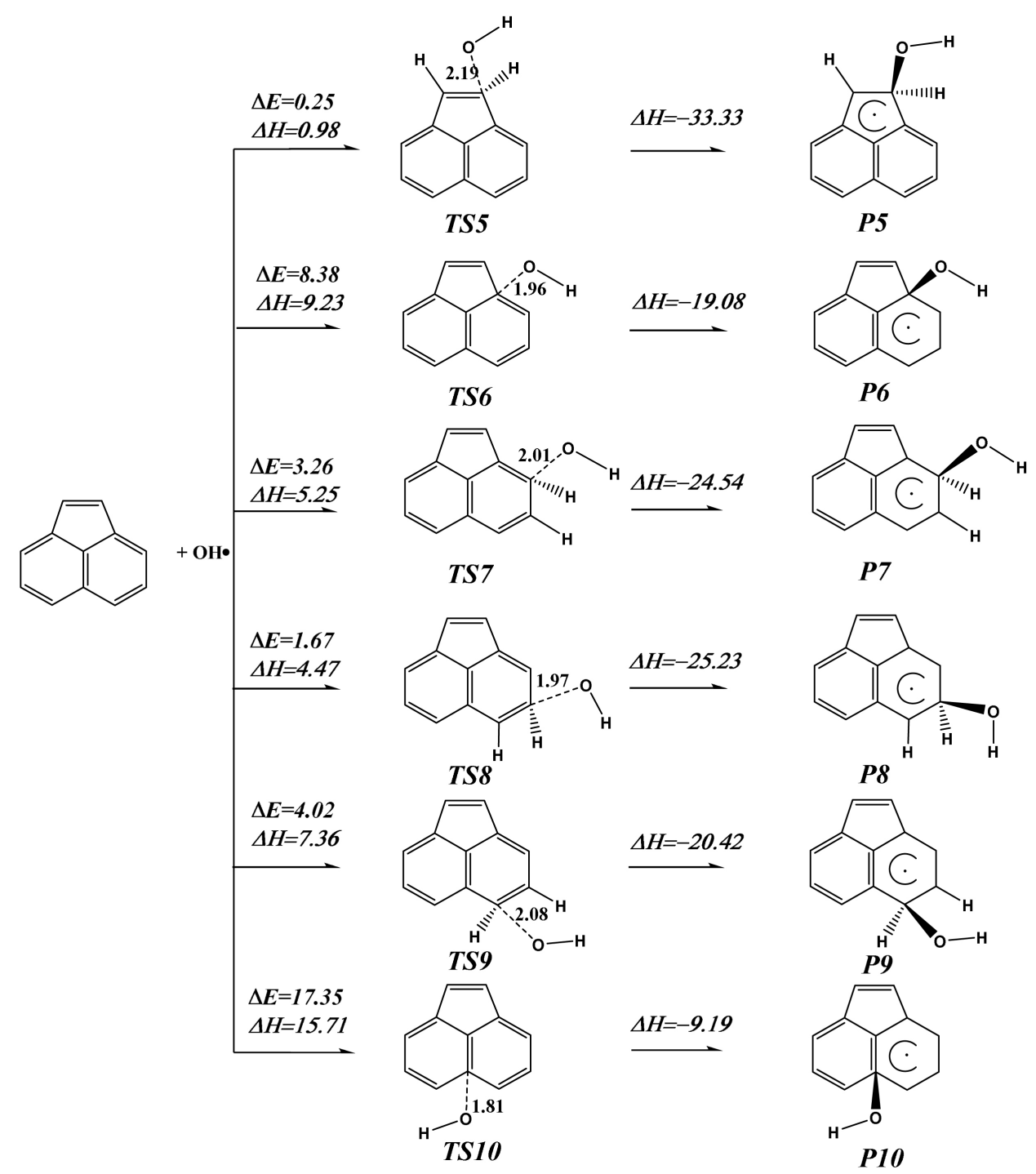

Figure 3. Proposed reaction pathways of $\mathrm{OH}$ addition to acenaphthylene at the M06-2X/augcc-pVTZ level of theory.

hydroxyl addition reaction is unlikely happened at C6 site. It is supposed that at general condition, the hydroxyl addition reaction is the dominant reaction pathway when the $\mathrm{OH}$ radical is provided. So in the next section, we focus on the further reaction possibility of the $\mathrm{OH}$-initiated acenaphthylene radicals.

\subsection{Decomposition of the $\mathrm{OH}$-Initiated Acenaphthylene Radical}

Because of sterically hindered and energetically unfavorable of the C2 and C6 sites, herein only the further reaction of P5, P7, P8 and P9 radicals will be discussed in this section. There are two possible reaction channels for the $\mathrm{H}$ atom decomposition from $\mathrm{OH}$-initiated acenaphthylene radical are proposed theoretically concerning P5 as the reactant described in Figure 4. The crucial difference for the transition states of the reactions is the $\mathrm{O}$ or $\mathrm{H}$ atom from the $\mathrm{C} 1$ site to connect the symmetrical $\mathrm{C}$ atom by forming a C-C-H or C-C-O three-member ring structure.

As the hypothetical reaction scheme, the mechanism of P11 formation is a concerted 


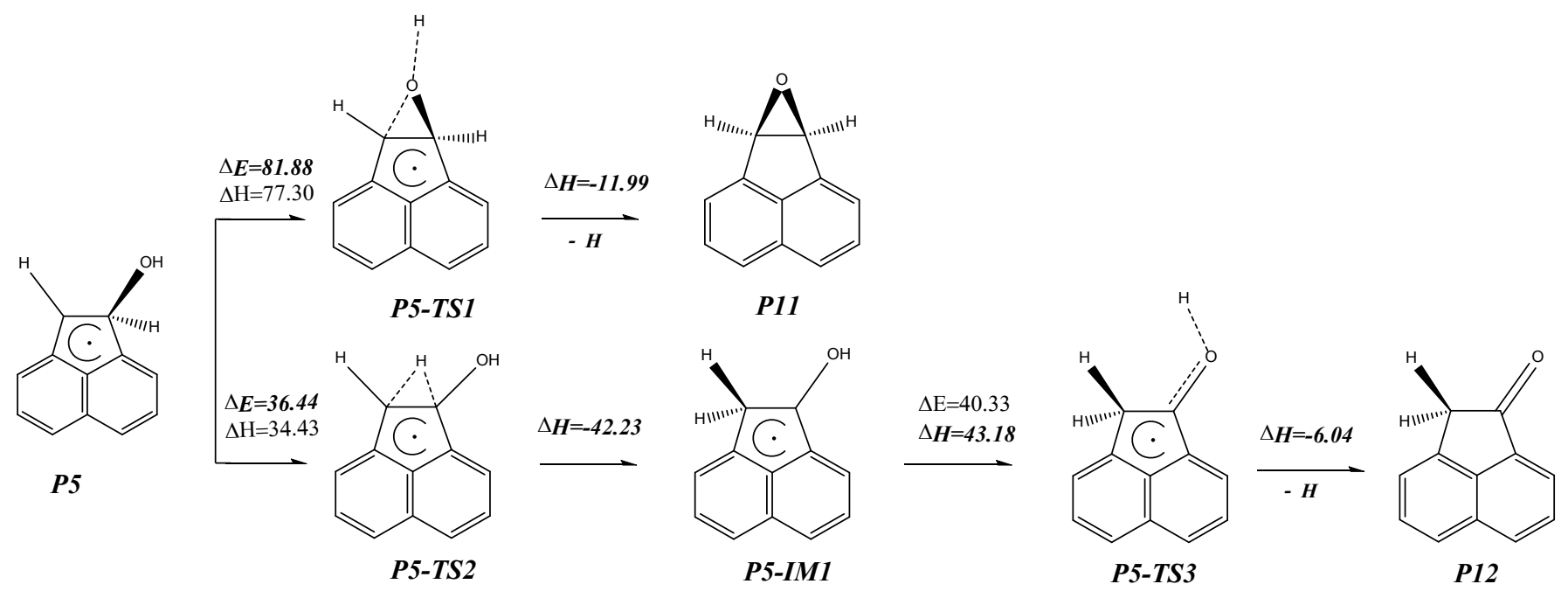

Figure 4. The $\mathrm{OH}$ addition reaction scheme of $\mathrm{P} 5$ embedded with energy barriers $\Delta E(\mathrm{kcal} / \mathrm{mol})$ and reaction enthalpies $\Delta H(\mathrm{kcal} / \mathrm{mol})$.

reaction with the $\mathrm{OH}$ migrates to form a three-member ring and the $\mathrm{H}$-atom of $\mathrm{OH}$ is taken away instantaneously. P12 formation is a two-step process, the first step is that the $\mathrm{H}$-atom from the carbon site which connecting the $\mathrm{OH}$ radical migrates to the adjacent carbon atom C1' (C2-site carbon is unallowed because of sterically hindered) to form the intermediate P5-IM1 through a C-C-H triatomic ring transition state P5-TS2, the $\mathrm{H}$ atom of $\mathrm{OH}$ in P5-IM1 will be away later through a transition state P5-TS3 to form neutral product 1-acenaphthenone (denoted as P12).

By using GC-MS technology, Zhou [19] has detected 1-acenaphthenone (denoted as P12) in the process of $\mathrm{OH}$-initiated acenaphthylene degradation in their experimental research. The calculated results show that the previous $\mathrm{P} 5$ radical can through a stepwise process to form $\mathrm{P} 12$ with the $\mathrm{H}$ atom migration followed by the $\mathrm{H}$ atom elimination from the hydroxyl of $\mathrm{C} 1$ site, there are $36.44 \mathrm{kcal} / \mathrm{mol}$ and $40.33 \mathrm{kcal} / \mathrm{mol}$ potential barriers, respectively, and the rate-determining step is the second process. The other pathway for P5 is crossing $81.88 \mathrm{kcal} / \mathrm{mol}$ of potential barrier to form P11 by a concerted reaction. P12 is a more stable isomer with the energy lower about $34.7 \mathrm{kcal} / \mathrm{mol}$ than P11. So, forming P12 and $\mathrm{H}$ radical is the energetically most favorable channel because of the lower barrier and stable product, which supporting the relevant experimental results perfectly.

Similarly, the decomposition of P7 and P9 both has two channels as well. The schemes of these processes can be identified as Figure 5 and Figure 6. Zhou [19] and Reisen [22] have detected P14 and epoxide (denoted as P13) in their experimental research works, respectively. Herein it is predicted theoretically that P7 needs to across $36.81 \mathrm{kcal} / \mathrm{mol}$ and $69.55 \mathrm{kcal} / \mathrm{mol}$ two barriers to form P14 with the second process acting as the rate-determining step. While the barrier to produce P13 is $101.33 \mathrm{kcal} /$ $\mathrm{mol}$, and P14 is a more stable isomer with the energy lower about $30.37 \mathrm{kcal} / \mathrm{mol}$ than P13. So, the pathway forming P14 is the energetically most favorable channel because of the lower barrier and a more stable product. The mechanisms here are similar compared with the previous discussion.

Due to C6-site carbon sterically hindered and energetically unfavorable, the decom- 


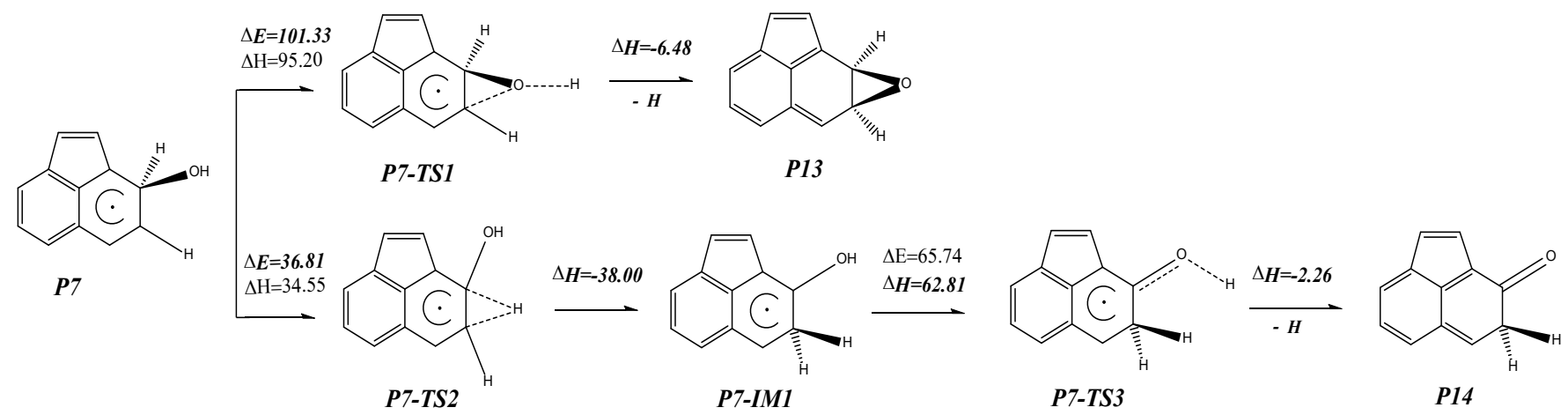

Figure 5. The $\mathrm{OH}$ addition reaction scheme of $\mathrm{P} 7$ embedded with energy barriers $\Delta E(\mathrm{kcal} / \mathrm{mol})$ and reaction enthalpies $\Delta H(\mathrm{kcal} / \mathrm{mol})$.

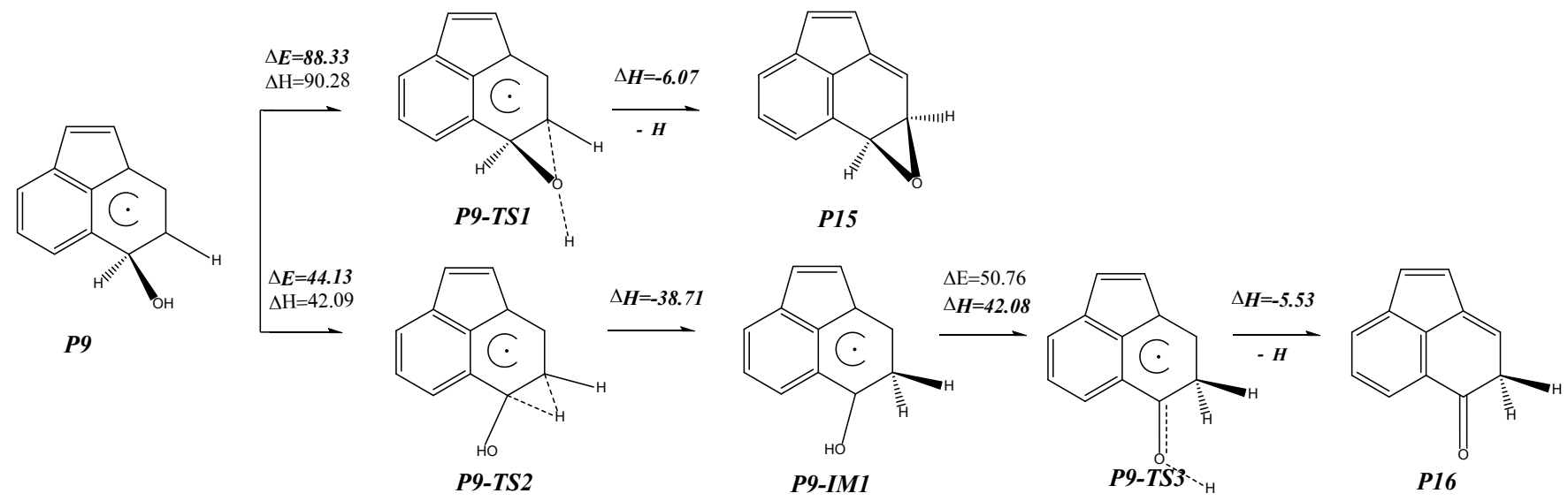

Figure 6. The $\mathrm{OH}$ addition reaction scheme of $\mathrm{P} 9$ embedded with energy barriers $\Delta E(\mathrm{kcal} / \mathrm{mol})$ and reaction enthalpies $\Delta H(\mathrm{kcal} / \mathrm{mol})$.

position of $\mathrm{P} 9$ is quite the same with $\mathrm{P} 7$. There are two reaction pathways to form the products $\mathrm{P} 15$ and P16 with the different reaction mechanism. The barrier to form epoxide $\mathrm{P} 15$ is $88.33 \mathrm{kcal} / \mathrm{mol}$, which is about $11.00 \mathrm{kcal} / \mathrm{mol}$ lower than P13. There are 44.13 and $50.76 \mathrm{kcal} / \mathrm{mol}$ of the reaction barriers to form acenaphthenone P16, P16 is a more stable isomer with the energy lower about $29.65 \mathrm{kcal} / \mathrm{mol}$ than P15. So, the pathway forming P16 is the energetically most favorable channel. Comparing the potential barriers of transition state to $\mathrm{P} 16$, there is not significant rate determinant reaction in this step-wise reaction pathway because of the comparable reaction barrier heights.

Unlike the reactions of $\mathrm{P} 5, \mathrm{P} 7$ and $\mathrm{P} 9$, there are multiple reaction probabilities for both reaction mechanism of the decomposition of P8. Both C3 and C5 sites can join the reaction with the $\mathrm{OH}$ on $\mathrm{C} 4$ site. The reactions shown in Figure 7, the epoxide with the concerted reaction could be the isomer P13 and P15, with the reaction barriers 96.04 and $79.68 \mathrm{kcal} / \mathrm{mol}$, respectively. In the stepwise reaction to form products acenaphthenone (denoted as P17 and P18), the rate-determining step is the second process of $\mathrm{H}$ abstraction from $\mathrm{OH}$-acenaphthylene adduct. The mechanism in detail is that the $\mathrm{H}$-atom of alkyl ring which connected an $\mathrm{OH}$ radical transfer to adjacent carbon through a three member ring (denoted as P8-TS3) to form P8-IM1. And then, $\mathrm{H}$-atom of $\mathrm{OH}$ radical is taken away through another transition state to form products acenaphthenone $\mathrm{P} 17$ by the ring carbonyl formation. There are $60.23 \mathrm{kcal} / \mathrm{mol}$ and 40.71 $\mathrm{kcal} / \mathrm{mol}$ potential barriers of the rate-determining step for the last two processes, 


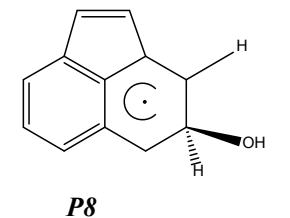

P8

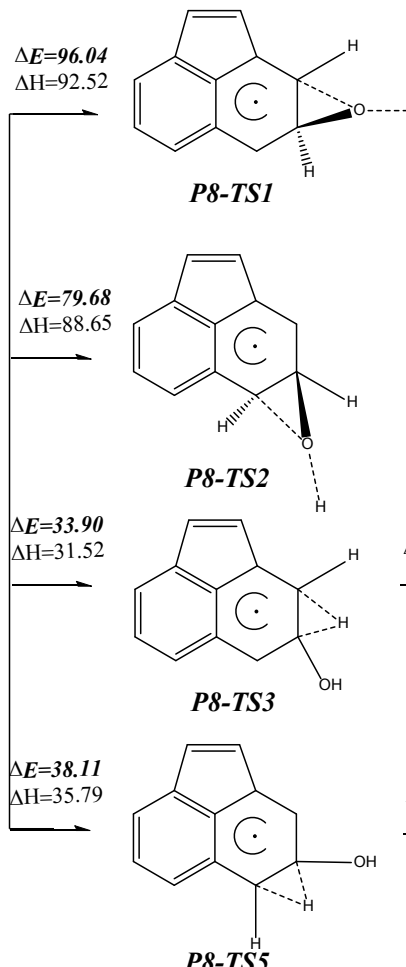

P8-TS5
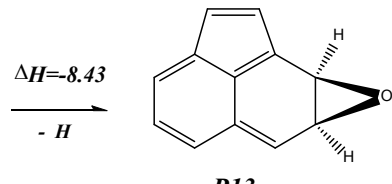

$P 13$

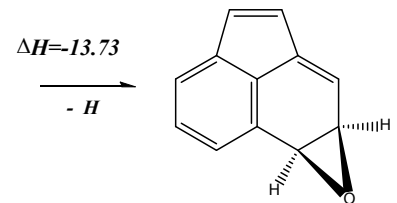

$P 15$

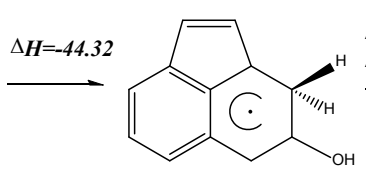

P8-IM1

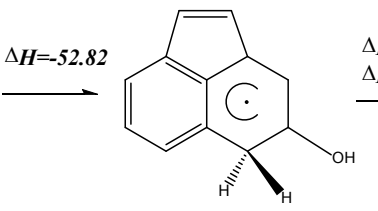

P8-IM2

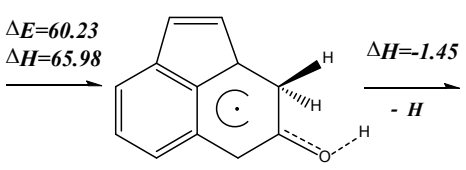

P8-TS4

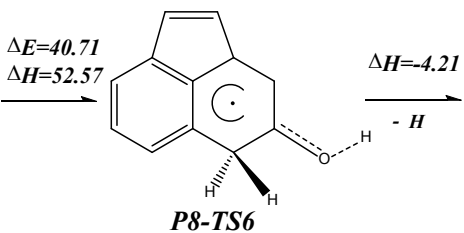

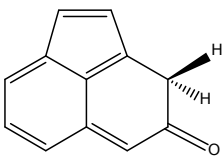

$P 17$

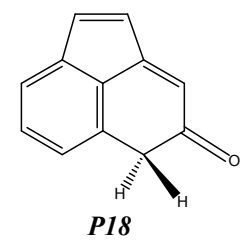

Figure 7. The $\mathrm{OH}$ addition reaction scheme of $\mathrm{P} 8$ embedded with activation energies $\Delta E(\mathrm{kcal} / \mathrm{mol})$ and reaction enthalpies $\Delta H$ $(\mathrm{kcal} / \mathrm{mol})$.

respectively. P18 is the most stable isomer with the energy lower about 51.54, 29.89 and $23.96 \mathrm{kcal} / \mathrm{mol}$ than P13, P15 and P17. The pathway of forming P18 is the energetically most favorable channel because of the lowest barrier and the most stable product.

In the earlier experimental research works mentioned above, Zhou [19] and Reisen [22] groups both declared that they have detected the OH-initiated acenaphthylene radical decomposition products acenaphthenone and epoxide respectively, and the two products gives the same relative molecular mass $(\mathrm{MW}=168)$ resulting in the configuration isomers. But herein with the DFT calculations, we predicted both reaction channels to produce all the possible product isomers, which results in the channels for the epoxide all having rather higher reaction barrier than for the acenaphthenone ones, which means because of more extra energy needed to overcome the high reaction barrier theoretically, it hardly to produce epoxide at the ordinary experimental condition as the reference works. The calculations suggested the $\mathrm{OH}$-acenaphthylene radical has a priority to form the acenaphthenone rather than epoxide. Certainly, to verify the conclusion we proposed, a series of IR or NMR detection in the process maybe epoxide inquired. In all of the acenaphthenone formed by $\mathrm{OH}$-initial acenaphthylene radical adducts, the most stable isomer is P12, it further illustrate that there is a tendency for the $\mathrm{OH}$ addition reaction on $\mathrm{C} 1$-site to form the most stable product as well.

\subsection{Secondary Reaction Pathways of $\mathrm{OH}$-Acenaphthylene}

\subsection{1. $\mathrm{OH}$-Acenaphthylene Reactions with $\mathrm{O}_{2}$ or $\mathrm{O}_{2} / \mathrm{NO}$}

It has been proofed by the Zhou [19] and Reisen [22] experimental works, that the predecessor $\mathrm{OH}$-initiated acenaphthylene can take place complex addition reactions with 
some micro-molecules in air. They detected that adducts of $\mathrm{OH}$-initial acenaphthylene can yield dialdehyde (denoted as P19), naphthalene-1,8-dicarbaldehyde (denoted as P20) and 1,8-naphthalic anhydride (denoted P21) in their experimental works. Herein, we propose the possible reaction pathways through the theoretical calculations to explain the mechanism about these products formation.

A series of mechanisms of P19 formation from the adduct P7 and $\mathrm{O}_{2}$ or $\mathrm{O}_{2} / \mathrm{NO}$ are demonstrated respectively in Figure 8. There are two spatial position (the trans-position and cis-position of $\mathrm{OH}$ ) for the $\mathrm{O}$ atom of $\mathrm{O}_{2}$ attacking the C4-site of P7, only the trans-position of $\mathrm{OH}$ is taken as the example in this paper because the cis-position has a relatively large sterically hindered as the comparison calculations. There are about 13.4 $\mathrm{kcal} / \mathrm{mol}$ and $0.43 \mathrm{kcal} / \mathrm{mol}$ lower in the energy of trans-P7-IM2 and trans-P7-TS4 than the corresponding cis-position transition state structure and product. The adduct $\mathrm{O}_{2}-\mathrm{P} 7$ will form through a transition state (denoted as P7-TS4) with the $26.64 \mathrm{kcal} / \mathrm{mol}$ potential barrier height and later intermediate P7-IM2 is formed by the C-O interaction enhanced.

There are two pathways can lead the aimed product P19. The first channel is the terminal $\mathrm{O}$ atom attacks the other side $\mathrm{H}$ atom of $\mathrm{OH}$ group to form a hexatomic ring transition state P7-TS5 by overcome $46.55 \mathrm{kcal} / \mathrm{mol}$ barrier height, by exothermic 8.16 $\mathrm{kcal} / \mathrm{mol}$ energy to release the $\mathrm{H}$ atom migrate to $\mathrm{O}_{2}$ side (denoted as P7-IM3). The aromatic ring will then experience a ring opening reaction to form P7-IM4 through a transition state (denoted as P7-TS6) with $\mathrm{C}=\mathrm{O}$ double bond is formed. In the end, the $\mathrm{OH}$ radical departures to form the aimed product (denoted as $\mathrm{P} 19)$. Another pathway is $\mathrm{P} 7$ reacts with $\mathrm{O}_{2}$ followed by the reaction with $\mathrm{NO}$ and one more $\mathrm{O}_{2}$ also can form<smiles></smiles>

P19

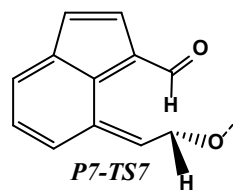

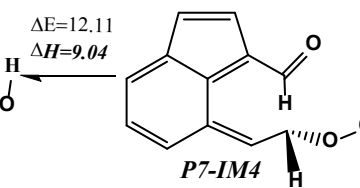

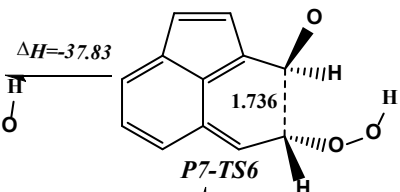
$\hat{1}_{\Delta \mathrm{E}=35.09}$ $\Delta \boldsymbol{H}=0.52$

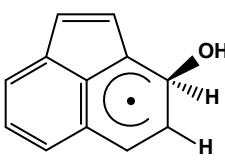

P7
$\underset{+\boldsymbol{O}_{2}}{\stackrel{\Delta \mathrm{E}=26.64}{\Delta \boldsymbol{H}=25.69}}$

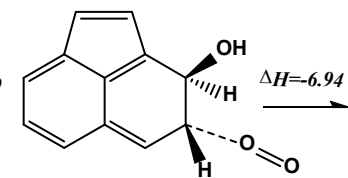

P7-TS4

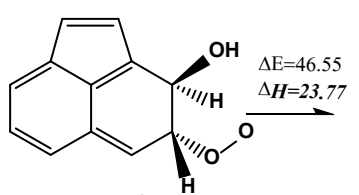

P7-IM2

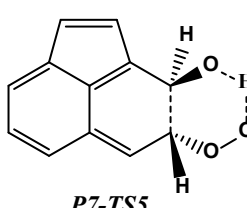

P7-TS5

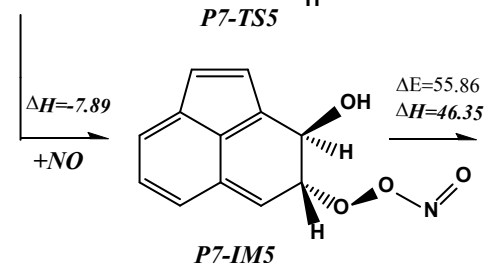

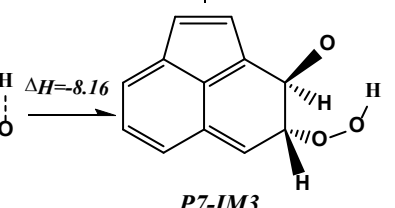

P7-IM3

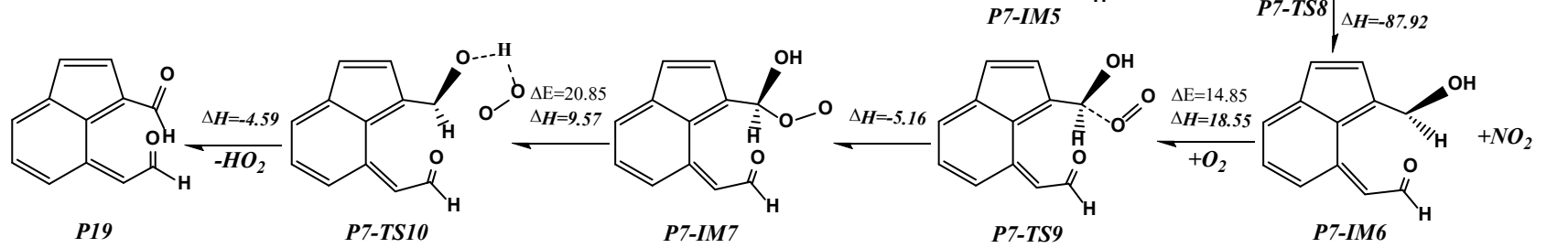

Figure 8. The secondary reaction scheme of $\mathrm{P} 7 \mathrm{embedded}$ with energy barriers $\Delta E(\mathrm{kcal} / \mathrm{mol})$ and reaction enthalpies $\Delta H(\mathrm{kcal} / \mathrm{mol})$. 
P19. After the formation of P7-IM2, $\mathrm{N}$ atom of $\mathrm{NO}$ can attack $\mathrm{O}_{2}$ side to form the adduct $\mathrm{NO}-\mathrm{O}_{2}-\mathrm{P} 7$ (denoted as P7-IM5) through a barrierless process. Then NO takes terminal $\mathrm{O}$-atom of $\mathrm{O}_{2}$ away to form $\mathrm{NO}_{2}$ and leaves P7-IM6 with the corresponding aromatic ring opening. Follow on, another $\mathrm{O}_{2}$ can attack the carbon atom which connecting to the $\mathrm{OH}$ radical through a transition state to form adduct (denoted as P7IM7). Later $\mathrm{O}_{2}$ will take $\mathrm{H}$ atom originally from $\mathrm{OH}$ away to form $\mathrm{HO}_{2}$ radical and then departure to form the aimed product P19.

Similarly, the possible pathways for $\mathrm{O}_{2}$ and $\mathrm{O}_{2} / \mathrm{NO}$ react with another $\mathrm{OH}$-intitated radical P5 is demonstrated in Figure 9. Due to the energy of trans-P5-TS4 is lower about $22.29 \mathrm{kcal} / \mathrm{mol}$ and the energy of trans-P5-IM2 is lower about $3.53 \mathrm{kcal} / \mathrm{mol}$ compared with the corresponding cis-position reaction isomers; herein we take transposition reaction for the example. $\mathrm{O}_{2}$ can attack on $\mathrm{C} 1$-site carbon from the trans-position to form the adduct $\mathrm{O}_{2}-\mathrm{P} 5$ through a transition state (denoted as P5-TS4) with only $13.76 \mathrm{kcal} / \mathrm{mol}$ barrier height. Then one $\mathrm{O}$ atom from $\mathrm{O}_{2}$ attacks the other side $\mathrm{H}$ atom of $\mathrm{OH}$ to form a hexatomic ring, the $\mathrm{H}$ atom migrates to $\mathrm{O}_{2}$ side (denoted as P5-IM3) by releasing $23.68 \mathrm{kcal} / \mathrm{mol}$ energy, meanwhile $\mathrm{C}=\mathrm{O}$ double bond formed, later the $\mathrm{OH}$ radical departures to form the aimed product (denoted as P20). In another pathway, P5 reacts with $\mathrm{O}_{2} / \mathrm{NO}, \mathrm{N}$ atom of $\mathrm{NO}$ can attack on $\mathrm{O}_{2}$ side to form adduct of $\mathrm{NO}-\mathrm{O}_{2}-\mathrm{P} 5$ (denoted as P5-IM4). The calculated results show that to form the adduct process is a barrierless reaction as well. Then $\mathrm{NO}$ will take away an $\mathrm{O}$ atom of $\mathrm{O}_{2}$ to form $\mathrm{NO}_{2}$ and departure from P5-IM4. Follow on, $\mathrm{O}_{2}$ can attack another side carbon atom which

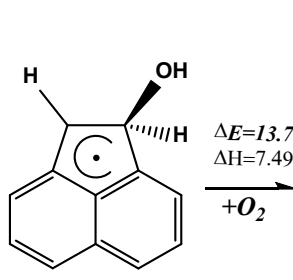

P5

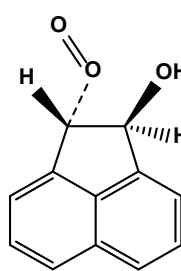

P5-TS4

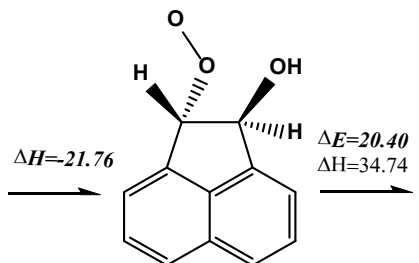

P5-IM2

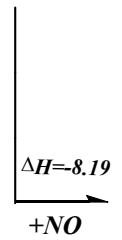

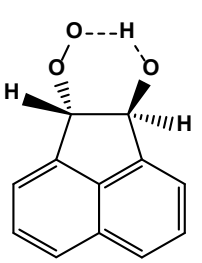

P5-TS5<smiles>O=NOO[C@H]1c2cccc3cccc(c23)[C@H]1O</smiles>

P5-IM4
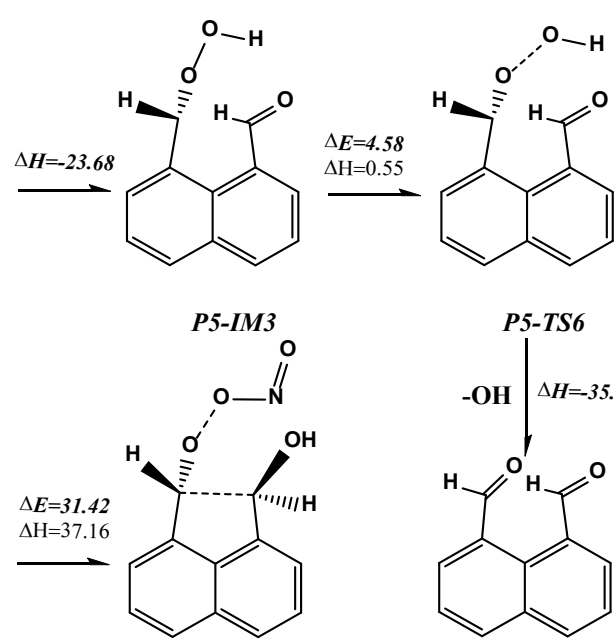

P5-TS7

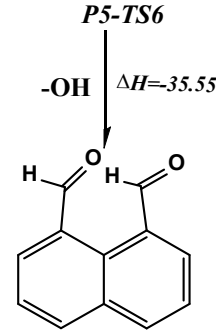

P20

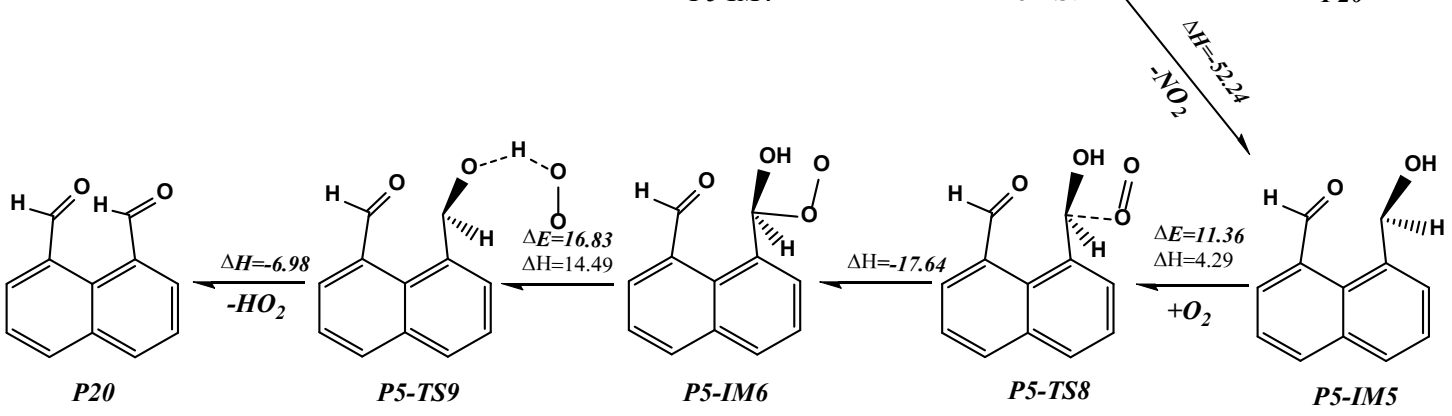

Figure 9. The secondary reaction scheme of $\mathrm{P} 5$ embedded with energy barriers $\Delta E(\mathrm{kcal} / \mathrm{mol})$ and reaction enthalpies $\Delta H(\mathrm{kcal} / \mathrm{mol})$. 
is connected the $\mathrm{OH}$ radical through a transition state to form adduct (denoted as P5-IM6). Later $\mathrm{O}_{2}$ will take $\mathrm{H}$ atom originally from $\mathrm{OH}$ away to form $\mathrm{HO}_{2}$ radical departure from the aimed product P20.

Compared with the pathways of $\mathrm{P} 7$ and $\mathrm{P} 5$ reacting with $\mathrm{O}_{2}$ from the thermodynamics point of view, there is not significant energy variation for the reactions, so in the troposphere, both of these two pathways are possible to form dialdehyde. But from the dynamics part, the reaction discussed above will both take place only when the concentration of $\mathrm{NO}$ is enough for the second pathway, otherwise, only the first pathway reaction will happen.

By the analyses of 1,8-naphthalic anhydride structure (denoted P21), the further possible reaction mechanism for P21 formation mechanism is proposed by taking P20 as the precursor as Figure 10. Firstly, $\mathrm{OH}$ radical attacks the one of the $\mathrm{H}$ atoms of aldehyde group in P20 by absorbing about $2.45 \mathrm{kcal} / \mathrm{mol}$ energy to form a transition state (denoted as $\mathrm{P} 20-\mathrm{TS} 1$ ), and then $\mathrm{OH}$ radical takes the $\mathrm{H}$ atom away to form a water molecule from the complex. Later $\mathrm{O}_{2}$ molecule attacks the $\mathrm{C}=\mathrm{O}$ bond of the energy-rich intermediate (denoted as P20-IM1) to form P20-IM2 through a transition state. In this process, forming P20-TS2 need absorb about $14.61 \mathrm{kcal} / \mathrm{mol}$ energy compared with the reactants. Where after, the terminal $\mathrm{O}$ atom attacks another side $\mathrm{H}$ atom to form an eight-member ring transition state (denoted as P20-TS3), and then $\mathrm{O}$ atom takes the $\mathrm{H}$ atom away remaining an aldehyde group radical. Finally, $\mathrm{C}-\mathrm{O}$ bond formed with $\mathrm{OH}$ radical departure to form the aimed product 1, 8-naphthalic anhydride (P21).

\subsection{2. $\mathrm{OH}$-Acenaphthylene Reactions with $\mathrm{NO}_{2}$}

It is found experimentally that there are two typical nitro-PAHs nitroacenaphthylene and nitroacenaphthylenol could be formed in the process of $\mathrm{OH}$-initialed PAH [19]. Accordingly, all the precursors P5, P7, P8 and P9 can take place $\mathrm{NO}_{2}$-adduct reactions with $\mathrm{NO}_{2}$ appearance. The mechanism about these nitro-PAHs can be clarified theoretically as Figure 11. There are trans- and the cis-two spatial positions for $\mathrm{N}$ atom of

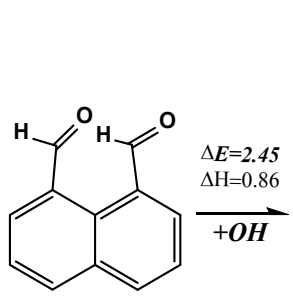

P20

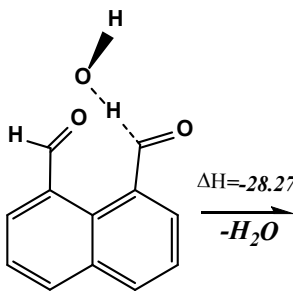

P20-TS1<smiles>O=Cc1cccc2cccc(C=O)c12</smiles>

P20-IM1

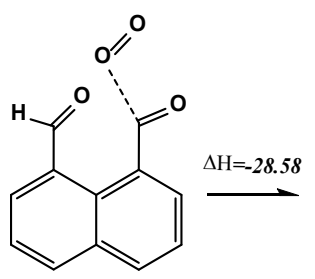

P20-TS2<smiles>O=Cc1cccc2cccc(C(=O)O)c12</smiles>

P20-IM2

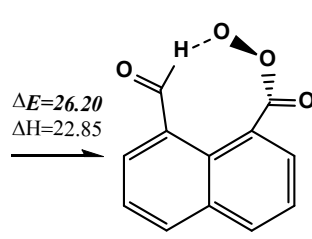

P20-TS3

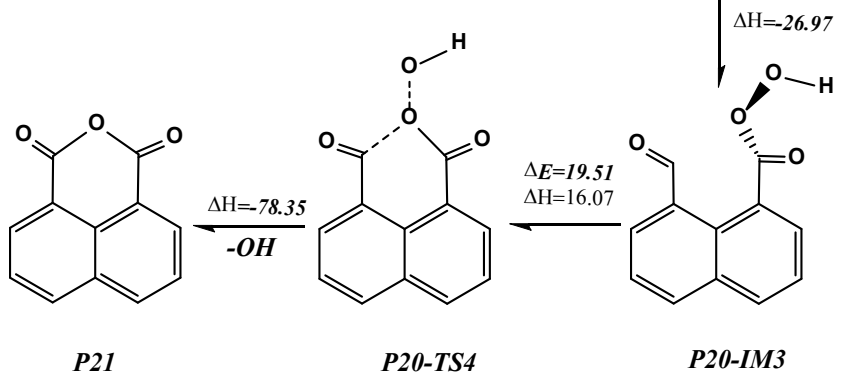

Figure 10. The secondary reaction scheme of $\mathrm{P} 20$ embedded with energy barriers $\Delta E(\mathrm{kcal} / \mathrm{mol})$ and reaction enthalpies $\Delta H(\mathrm{kcal} / \mathrm{mol})$. 

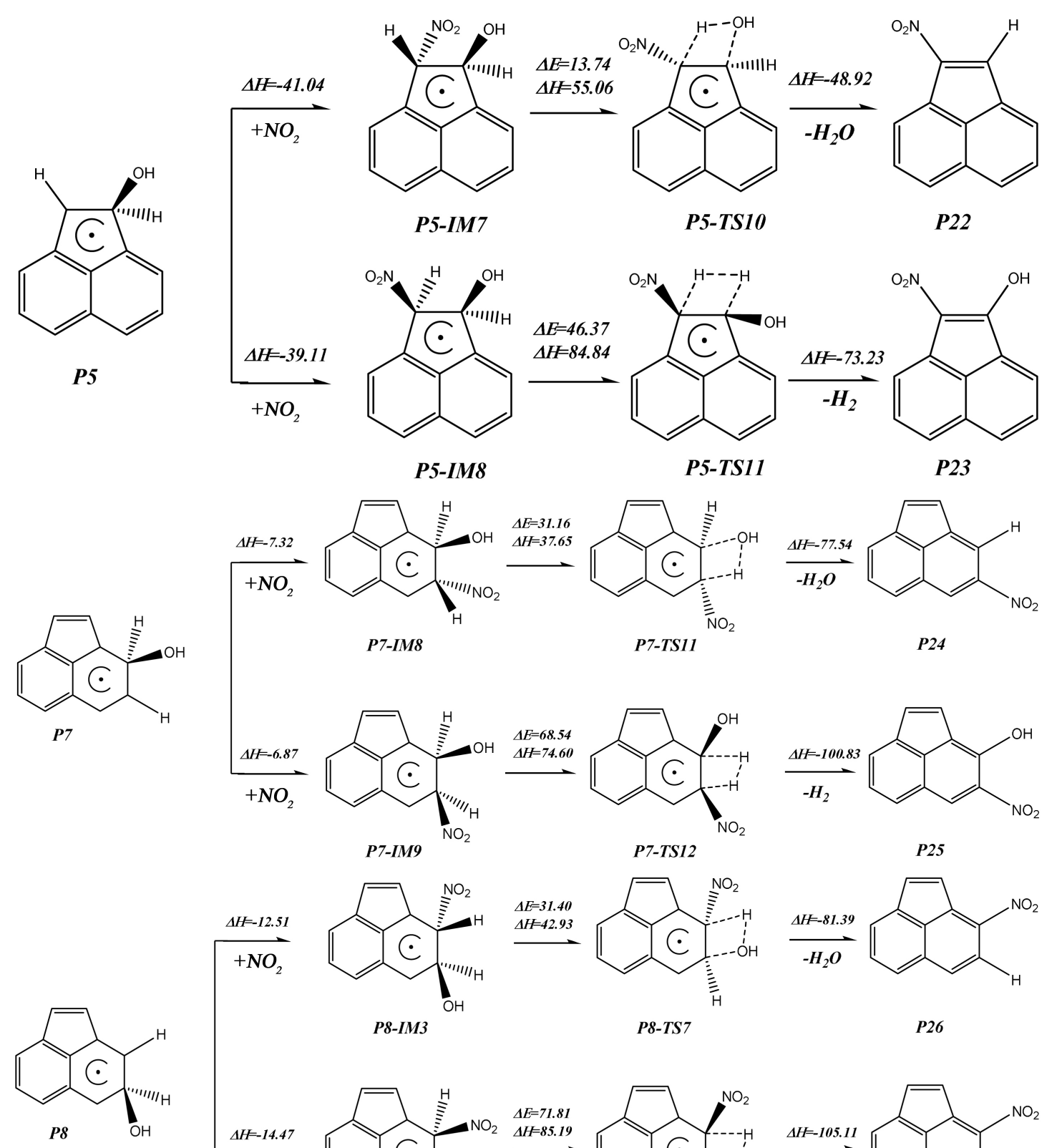
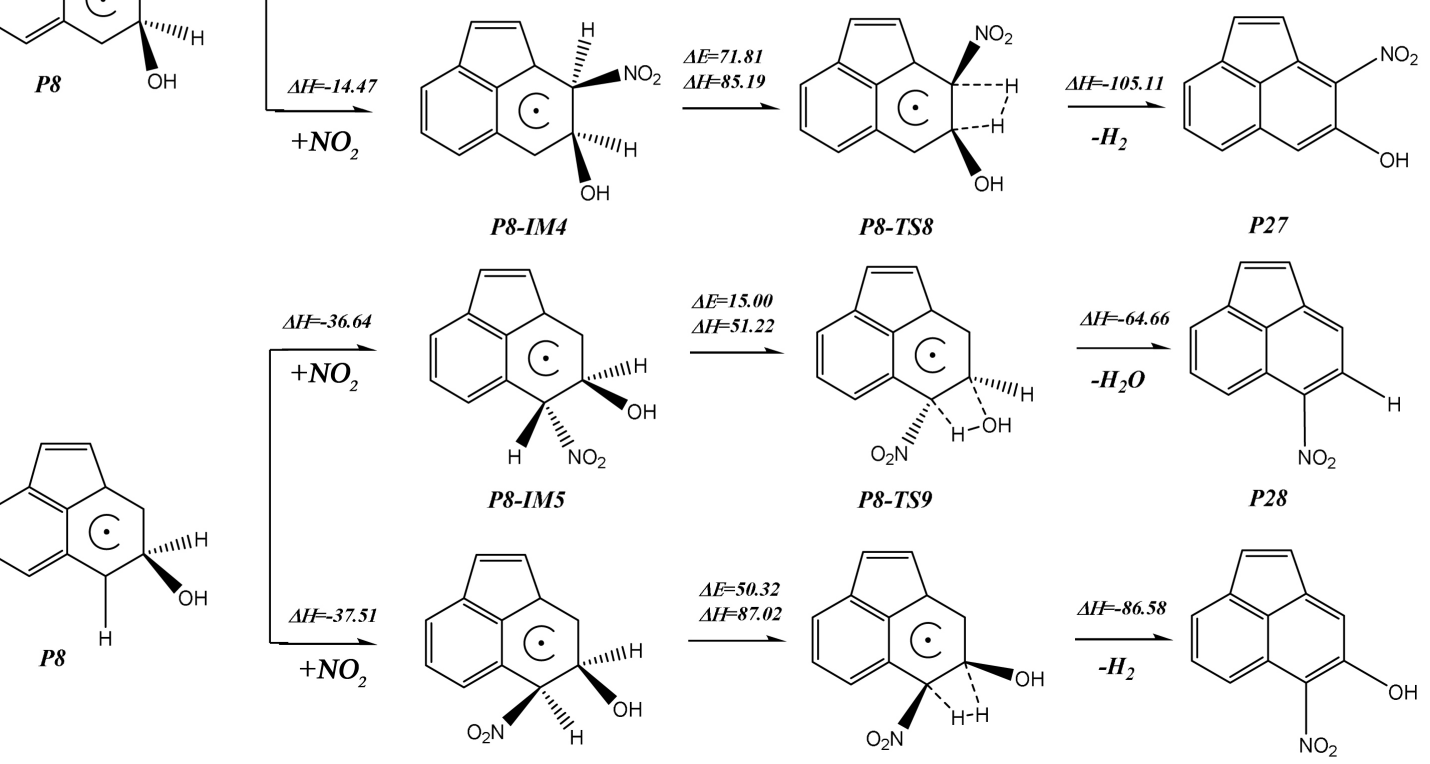

P8-IM6
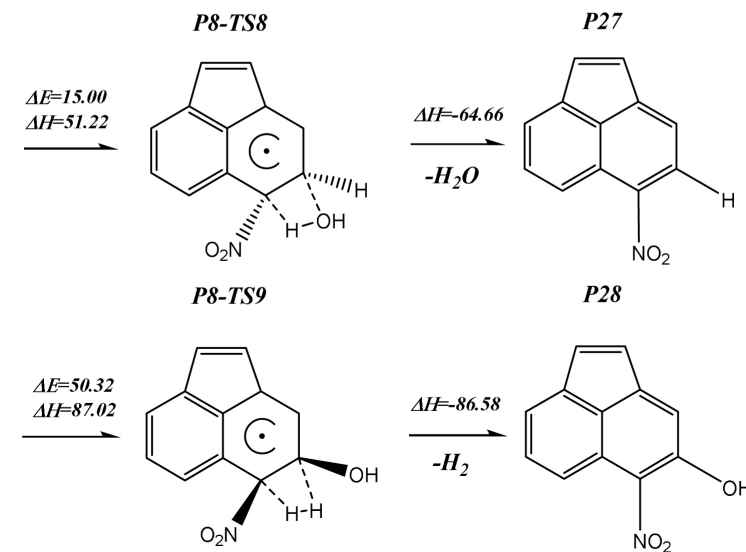

P8-TS10

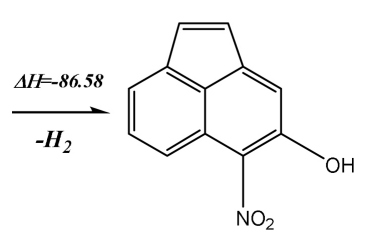

P29 


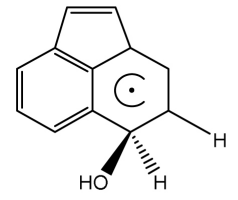

P9
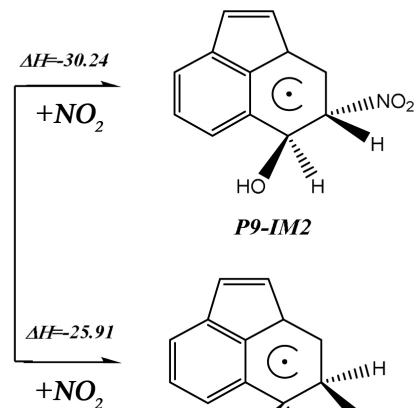

P9-IM2

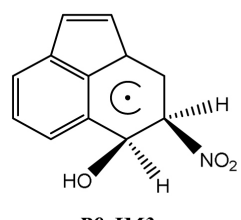

PQ-IM3

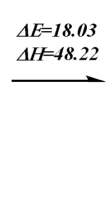

$=18.03$

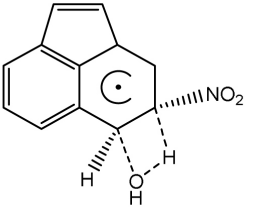<smiles></smiles>

P9-TS4

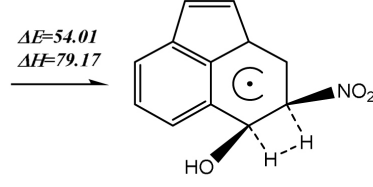

P9-TS5

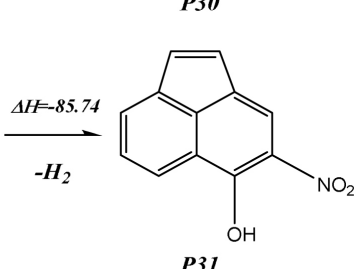

P31

Figure 11. The secondary reaction scheme of $\mathrm{P} 5, \mathrm{P} 7, \mathrm{P} 8, \mathrm{P} 9$ and $\mathrm{NO}_{2}$ embedded with energy barriers $\Delta E$ ( $\mathrm{kcal} / \mathrm{mol})$ and reaction enthalpies $\Delta H(\mathrm{kcal} / \mathrm{mol})$.

$\mathrm{NO}_{2}$ attacking on the adjacent carbon atom bonding the $\mathrm{OH}$ group of adduct. Thus, two kinds of products are formed named nitroacenaphthylene and nitroacenaphthylenol through the different reaction pathways. First of all, $\mathrm{NO}_{2}$ attaches to the precursors to form the corresponding adducts with comparable stabilized energy from different sides of the $\mathrm{OH}$ group. Later, the $\mathrm{H}$ atom of the $\mathrm{NO}_{2}$ reaction site will attach the same side $\mathrm{H}$ atom or $\mathrm{O}$ atom of $\mathrm{OH}$ group to form the typical $\mathrm{C}-\mathrm{C}-\mathrm{H}-\mathrm{H}$ or $\mathrm{C}-\mathrm{C}-\mathrm{O}-\mathrm{H}$ four-atomic ring transition states with significant difference of the reaction barrier height, after that there are $\mathrm{H}_{2}$ or $\mathrm{H}_{2} \mathrm{O}$ formed and departed to obtain a series of isomer products.

The calculated results show that it is a barrierless process for $\mathrm{NO}_{2}$ attacking the corresponding precursors to form the relatively stable adducts. The stability is diverse from each other, where adducts derived from P5 and P8 (associated with C5 site) are more stable than the others, while adducts from P7 are the most unstable ones. P5, P7 and P9 are all favor to form adducts from the trans-position of the $\mathrm{OH}$ group but P8. All the precursors are favor to form the nitroacenaphthylene isomers from the reaction barriers comparison, where P7 has the relatively lowest reaction barrier. The reaction barriers for the nitroacenaphthylenol formation are relatively higher than the corresponding nitroacenaphthylene ones about 30.0 to $40.0 \mathrm{kcal} / \mathrm{mol}$; again $\mathrm{P} 7$ has the comparatively lowest reaction barrier.

It is found that the most stable isomers for both nitroacenaphthylene and nitroacenaphthylenol are from $\mathrm{P} 5$ reacting with $\mathrm{NO}_{2}$ by the stability comparison of all the products $\mathrm{P} 22$ to $\mathrm{P} 31$. When $\mathrm{NO}_{2}$ attacks $\mathrm{P} 5$ to form P5-IM7 and P5-IM8, there are $41.04 \mathrm{kcal} / \mathrm{mol}$ and $39.11 \mathrm{kcal} / \mathrm{mol}$ energy released at the beginning of the reaction. As a trans-position adduct, P5-IM7 will decompose to produce nitroacenaphthylene (denoted as P22) through a $13.74 \mathrm{kcal} / \mathrm{mol}$ potential barrier, while the cis-position adduct P5-IM8 needs to across an especially higher potential barrier $46.37 \mathrm{kcal} / \mathrm{mol}$ to form nitroacenaphthylenol (denoted as P23). Comparing these two reaction pathways, we draw a prediction that the nitroacenaphthylene is the relatively high abundance of products for $\mathrm{PAH}$ reacting with $\mathrm{NO}_{2}$.

\section{Conclusion}

The systematical reactions of $\mathrm{OH}$-initiated atmospheric oxidation degradation of ace- 
naphthylene have been studied theoretically by using DFT method at M06-2X/augcc-pVTZ level. First of all, there are two types of reactions proposed with $\mathrm{OH}$ radical (denoted as $\mathrm{H}$-abstraction and $\mathrm{OH}$-addition), and the calculated results show that $\mathrm{OH}$ has a favor to follow the $\mathrm{OH}$-addition pathway to form $\mathrm{OH}$-initiated radicals. Among all the reaction sites, the $\mathrm{H}$ abstraction on the $\mathrm{C} 3$-site and $\mathrm{OH}$ addition to the $\mathrm{C} 1$-site are more likely to occur than others. Meanwhile, the decomposition of P5 as well as P7-P9 radicals have been discussed in detailed. The favorable reaction is confirmed to form the acenaphthenone rather than epoxide with the most stable isomer is the reaction on the $\mathrm{C} 1$-site. Furthermore, P5 and P7 are selected to describe the possible further reaction processes with $\mathrm{O}_{2} / \mathrm{NO}$, whenever the concentration of $\mathrm{NO}$ is enough for the second pathway, the two possible reaction pathways will both take place, otherwise, there is only the reaction with $\mathrm{O}_{2}$. The possible products can be epoxide, naphthalene-1,8-dicarbaldehyde, dialdehydes, 1-acenaphthenone and some nitroacenaphthylene in general condition reaction. It is predicted that the advantage reaction pathway for $\mathrm{OH}$-acenaphthylene adducts reacting with $\mathrm{NO}_{2}$ is to form nitroacenaphthylene and nitroacenaphthylenol isomers by P5. In theoretical point of view, the primary calculated results can support the relative experimental researches to identify the reaction mechanism well. Certainly, to verify the conclusion we proposed, a series of kinetic study to simulate the whole process is further inquired.

\section{Acknowledgements}

The authors thank to the generous computing time supporting from the Supercomputing Center of University of Science and Technology of China.

\section{References}

[1] Atkinson, R. (1990) Gas-Phase Tropospheric Chemistry of Organic Compounds: A Review. Atmospheric Environment. Part A. General Topics, 24, 1-41. https://doi.org/10.1016/0960-1686(90)90438-S

[2] Motorykin, O., Matzke, M.M., Waters, K.M. and Massey Simonich, S.L. (2013) Association of Carcinogenic Polycyclic Aromatic Hydrocarbon Emissions and Smoking with Lung Cancer Mortality Rates on a Global Scale. Environmental Science \& Technology, 47, 34103416.

[3] Dang, J., Shi, X.L., Hu, J.T., Chen, J.M., Zhang, Q.Z. and Wang, W.X. (2015) Mechanistic and Kinetic Studies on OH-Initiated Atmospheric Oxidation Degradation of Benzo[a]pyrene in the Presence of $\mathrm{O}_{2}$ and $\mathrm{NO}_{\mathrm{x}}$. Chemosphere, 119, 387-393. https://doi.org/10.1016/j.chemosphere.2014.07.001

[4] Arey, J., Zielinska, B., Atkinson, R. and Aschmann, S.M. (1989) Nitroarene Products from the Gas-Phase Reactions of Volatile Polycyclic Aromatic Hydrocarbons with the OH Radical and $\mathrm{N}_{2} \mathrm{O}_{5}$. International Journal of Chemical Kinetics, 21, 775-799. https://doi.org/10.1002/kin.550210906

[5] Nishioka, M.G., Howard, C.C., Contos, D.A., Ball, L.M. and Lewtas, J. (1988) Detection of Hydroxylated Nitro Aromatic and Hydroxylated Nitro Polycyclic Aromatic Compounds in an Ambient Air Particulate Extract Using Bioassay-Directed Fractionation. Environmental Science \& Technology, 22, 908-915. https://doi.org/10.1021/es00173a007

[6] Yamasaki, H., Kuwata, K. and Miyamoto, H. (1982) Effects of Ambient Temperature on Aspects of Airborne Polycyclic Aromatic Hydrocarbons. Environmental Science \& Tech- 
nology, 16, 189-194. https://doi.org/10.1021/es00098a003

[7] Atkinson, R. and Arey, J. (1994) Atmospheric Chemistry of Gas-Phase Polycyclic Aromatic Hydrocarbons: Formation of Atmospheric Mutagens. Environmental Health Perspectives, 102, 117-126. https://doi.org/10.1289/ehp.94102s4117

[8] Atkinson, R., Aschmann, S.M., Arey, J., Barbara, Z. and Schuetzle, D. (1989) Gas-Phase Atmospheric Chemistry of 1- and 2-Nitronaphthalene and 1,4-Naphthoquinone. Atmospheric Environment, 23, 2679-2690. https://doi.org/10.1016/0004-6981(89)90548-9

[9] Qu, X.H., Zhang, Q.Z. and Wang, W.X. (2006) Mechanism for OH-Initiated Photooxidation of Naphthalene in the Presence of $\mathrm{O}_{2}$ and $\mathrm{NO}_{\mathrm{x}}$ : A DFT Study. Chemical Physics Letters, 429, 77-85. https://doi.org/10.1016/j.cplett.2006.08.036

[10] Shiroudi, A. and Deleuze, M.S. (2014) Theoretical Study of the Oxidation Mechanisms of Naphthalene Initiated by Hydroxyl Radicals: The H Abstraction Pathway. The Journal of Physical Chemistry A, 118, 3625-3636. https://doi.org/10.1021/jp500124m

[11] Shiroudi, A., Deleuze, M.S. and Canneaux, S. (2014) Theoretical Study of the Oxidation Mechanisms of Naphthalene Initiated by Hydroxyl Radicals: The OH-Addition Pathway. The Journal of Physical Chemistry A, 118, 4593-4610. https://doi.org/10.1021/jp411327e

[12] Zhang, Q.Z., Gao, R., Xu, F., Zhou, Q., Jiang, G.B., Wang, T., Chen, J.M., Hu, J.T., Jiang, W. and Wang, W.X. (2014) Role of Water Molecule in the Gas-Phase Formation Process of Nitrated Polycyclic Aromatic Hydrocarbons in the Atmosphere: A Computational Study. Environmental Science \& Technology, 48, 5051-5057. https://doi.org/10.1021/es500453g

[13] Carissan, Y. and Klopper, W. (2010) Hydrogen Abstraction from Biphenyl, Acenaphthylene, Naphthalene and Phenanthrene by Atomic Hydrogen and Methyl Radical: DFT and G3 (MP2)-RAD Data. Journal of Molecular Structure: THEOCHEM, 940, 115-118. https://doi.org/10.1016/j.theochem.2009.10.017

[14] Lee, J. and Lane, D.A. (2010) Formation of Oxidized Products from the Reaction of Gaseous Phenanthrene with the $\mathrm{OH}$ Radical in a Reaction Chamber. Atmospheric Environment, 44, 2469-2477. https://doi.org/10.1016/j.atmosenv.2010.03.008

[15] Kameda, T., Inazu, K., Asano, K., Murota, M., Takenaka, N., Sadanaga, Y., Hisamatsu, Y. and Bandow, H. (2013) Prediction of Rate Constants for the Gas Phase Reactions of Triphenylene with $\mathrm{OH}$ and $\mathrm{NO}_{3}$ Radicals Using a Relative Rate Method in $\mathrm{CCl}_{4}$ Liquid PhaseSystem. Chemosphere, 90, 766-771. https://doi.org/10.1016/j.chemosphere.2012.09.071

[16] Dang, J., Shi, X.L., Zhang, Q.Z., Hu, J.T. and Wang, W.X. (2015) Mechanism and Kinetic Properties for the OH-Initiated Atmospheric Oxidation Degradation of 9, 10-Dichlorophenanthrene. Science of the Total Environment, 505, 787-794. https://doi.org/10.1016/j.scitotenv.2014.10.081

[17] Liu, C., Li, S.Q., Gao, R., Dang, J., Wang, W.X. and Zhang, Q.Z. (2014) Mechanism and Kinetic Properties of $\mathrm{NO}_{3}$-Initiated Atmospheric Degradation of DDT. Journal of Environmental Sciences, 26, 601-607. https://doi.org/10.1016/S1001-0742(13)60388-5

[18] Dang, J., Shi, X.L., Zhang, Q.Z., Hu, J.T. and Wang, W.X. (2015) Mechanism and Thermal Rate Constant for the Gas-Phase Ozonolysis of Acenaphthylene in the Atmosphere. Science of the Total Environment, 514, 344-350. https://doi.org/10.1016/j.scitotenv.2014.12.009

[19] Zhou, S. and Wenger, J.C. (2013) Kinetics and Products of the Gas-Phase Reactions of Acenaphthylene with Hydroxyl Radicals, Nitrate Radicals and Ozone. Atmospheric Environment, 75, 103-112. https://doi.org/10.1016/j.atmosenv.2013.04.049

[20] Shiraiwa, M., Garland, R.M. and Pöschl, U. (2009) Kinetic Double-Layer Model of Aerosol Surface Chemistry and Gas-Particle Interactions (K2-SURF): Degradation of Polycyclic Aromatic Hydrocarbons Exposed to $\mathrm{O}_{3}, \mathrm{NO}_{2}, \mathrm{H}_{2} \mathrm{O}, \mathrm{OH}$ and $\mathrm{NO}_{3}$. Atmospheric Chemistry and Physics, 9, 9571-9586. https://doi.org/10.5194/acp-9-9571-2009

[21] Atkinson, R. (2000) Atmospheric Chemistry of VOCs and $\mathrm{NO}_{\mathrm{x}}$. Atmospheric. Environ- 
ment, 34, 2063-2101. https://doi.org/10.1016/S1352-2310(99)00460-4

[22] Reisen, F. and Arey, J. (2002) Reactions of Hydroxyl Radicals and Ozone with Acenaphthene and Acenaphthylene. Environmental Science \& Technology, 36, 4302-4311. https://doi.org/10.1021/es025761b

[23] Frisch, M.J., Trucks, G.W., Schlegel, H.B., Scuseria, G.E., Robb, M.A., Cheeseman, J.R., Scalmani, G., Barone, V., Mennucci, B., Petersson, G.A., Nakatsuji, H., Caricato, M., Li, X., Hratchian, H.P., Izmaylov, A.F., Bloino, J., Zheng, G., Sonnenberg, J.L., Hada, M., Ehara, M., Toyota, K., Fukuda, R., Hasegawa, J., Ishida, M., Nakajima, T., Honda, Y., Kitao, O., Nakai, H., Vreven, T., Montgomery, J.A.J., Peralta, J.E., Ogliaro, F., Bearpark, M., Heyd, J.J., Brothers, E., Kudin, K.N., Staroverov, V.N., Keith, T., Kobayashi, R., Normand, J., Raghavachari, K., Rendell, A., Burant, J.C., Iyengar, S.S., Tomasi, J., Cossi, M., Rega, N., Millam, J.M., Klene, M., Knox, J.E., Cross, J.B., Bakken, V., Adamo, C., Jaramillo, J., Gomperts, R., Stratmann, R.E., Yazyev, O., Austin, A.J., Cammi, R., Pomelli, C., Ochterski, J.W., Martin, R.L., Morokuma, K., Zakrzewski, V.G., Voth, G.A., Salvador, P., Dannenberg, J.J., Dapprich, S., Daniels, A.D., Farkas, O., Foresman, J.B., Ortiz, J.V., Cioslowski, J. and Fox, D.J. (2009) Gaussian 09, Revision A.02. Gaussian, Inc., Wallingford.

[24] Zhao, Y. and Truhalr, D.G. (2008) The M06 Suite of Density Functionals for Main Group Thermochemistry, Thermochemical Kinetics, Noncovalent Interactions, Excited States, and Transition Elements: Two New Functionals and Systematic Testing of Four M06-Class Functionals and 12 Other Functionals. Theoretical Chemistry Accounts, 120, 215-241. https://doi.org/10.1007/s00214-007-0310-X

[25] Priya, A.M. and Senthilkumar, L. (2015) Reaction of OH Radical and Ozone with Methyl Salicylate-A DFT Study. Journal of Physical Organic Chemistry, 28, 542-553. https://doi.org/10.1002/poc.3447

[26] Sandhiya, L., Kolandaivel, P. and Senthilkumar, K. (2013) Mechanism and Kinetics of the Atmospheric Oxidative Degradation of Dimethylphenol Isomers Initiated by $\mathrm{OH}$ Radical. The Journal of Physical Chemistry A, 117, 4611-4626. https://doi.org/10.1021/jp3120868

\section{Submit or recommend next manuscript to SCIRP and we will provide best service for you:}

Accepting pre-submission inquiries through Email, Facebook, LinkedIn, Twitter, etc. A wide selection of journals (inclusive of 9 subjects, more than 200 journals)

Providing 24-hour high-quality service

User-friendly online submission system

Fair and swift peer-review system

Efficient typesetting and proofreading procedure

Display of the result of downloads and visits, as well as the number of cited articles

Maximum dissemination of your research work

Submit your manuscript at: http://papersubmission.scirp.org/

Or contact cc@scirp.org 